\section{Review: Das Public Health Buch}

The authoritative text in public health science has finally been challenged, albeit not in English. The German Das Public Health Buch may be regarded as the modernized version of the somewhat stuffy Oxford Textbook of Public Health.

Schwartz and his colleagues have compiled an impressive work (702 pages!) that at first sight covers the entire spectrum of both old and new public health. Publication of the book may be considered the hallmark of the re-emergence of public health as a full-grown (academic) field in Germany. With a glorious past of the field, public health development was abruptly halted there with the National-Socialist ideology of "Sozialhygiene" in the 1930s and 1940s. The "Health Movement" (Gesundheitsbewegung) emerging in the 1970s and 1980s sparked a new interest in public health, and the exploding numbers of Schools of Public Health in Germanspeaking parts of Europe in the 1990s show that public health is back. Even more, public health development in Germany and its neighbours has not been suffering from the Law of Diminishing Returns: an entirely new start was possible, and the continuous reference to concepts of New Public Health throughout the book shows that innovation has found fertile soil in the countries at which the book is aiming.

The book comprises of eight equally important parts, with in total 29 chapters and an informative service chapter (with addresses, Internet links, a glossary and index). The sections (translated into English) deal with

- Health and disease

- Institutions, systems and structures

- Collecting and interpreting information

- What can public health achie $e$ in practice? Disease perspecti es
- What can public health achie $e$ in practice? Population perspecti es

- What can public health achie $e$ in practice? Systems and institutional perspecti es

- Education and training in public health

The structure and format of the book lend it very well for use in training settings. Clear boxes and graphs illustrate important issues and highlight definitions and unresolved problems in the field.

Yet, perhaps because of the germanocentric perspective of the book, a few critical issues should be considered for a second edition. The strong tradition in health education planning so pervasive in other parts of the world is fully lacking (any reference to the father of modern health education, Lawrence Green, is absent), and advances made over the last decades in health and social psychology are only dealt with superficially. Perhaps because of the fact that it is hardly employed in Germany, a critical appraisal of community development programmes (traditional ones, such as North Karelia and Minnesota Heart Health, and more modern ones, such as Healthy Cities and British examples) is not dealt with. Whereas empowerment and intersectoral action are buzzwords throughout the world these days, the editors of Das Public Health Buch have not incorporated any reference to these issues. Truly a chance passed by, at least this time.

Nevertheless, this is a very impressive book that shows full commitment to innovation in public health.

Evelyne de Leeuw

Schwartz (editor)

Das Public Health Buch

Gesundheit und Gesundheitswesen

Urban \& Schwarzenberg, Verlag für Medizin, München, Wien, Baltimore

1997, ISBN 3-541-17441-2

DM 168, öS 1226, Sfr 149 